\title{
Inheritance and Innovation of the Artistic Style of Lingnan Architecture
}

\author{
Minglei Jiang \\ Neusoft Institute of Guangdong \\ Foshan, China 528225
}

\author{
Xuchang Li \\ Guangdong Polytechnic College \\ Zhaoqing, China, 526100
}

\begin{abstract}
Design is "innovation in life styles". In terms of the science of human affairs, this paper examines the inheritance and innovation of the artistic style of Lingna architecture against the context of the binary oppositionof architecture and environment, the traditional and the modern, and the local and the global.
\end{abstract}

Keywords - Lingnan architecture; artistic style; science of human affairs; inheritance; innovation

\section{INTRODUCTION}

Lingnan culture has a long history. Subject to the influence of its climate and geographical position, Lingnan has evolved a culture from a distinct background. During Central Plains culture blending with overseas cultures, transformed and restructured, Lingnan culture had inherited and developed the traditional culture and has evolved its distinct styles today. Nowadays, against the context of the binary opposition of architecture and environment, the traditional and the modern, and the local and the global, as an important carrier of inheriting Lingnan culture, how does Lingnan architecture face the globalized world, both inherit the traditional and interpret the modern, and take a global view on a domestic basis? It is of certain theoretical significance and practical value to see problems, probe into the thread of the inheritance and innovation of the artistic style of Lingnan architecture, and build up new ideas of the architectural style based on Lingnan culture.

\section{THE SCIENCE OF HuMAN AFFAIRS ABOUT THE ARTISTIC STYLE OF LINGNANARCHITECTURE}

Design is "innovation in life styles". In terms of the science of human affairs, "affairs" are the starting point of design thinking and study. They analyze, sum up, and judge the related factors behind "objects", for example, people, time, sites, social environment, etc., and have what relationship with "objects". Only studying, finding, and understanding the thread in the relationship between the "explicit relationship" and the "hidden logic" between people and objects can create fair and reasonable "objects".

The artistic style of Lingnan architecture is what has been created from the "relationship field" of "affairs". The Xiguan Mansion in Guangzhou is a typical representative of the artistic style of Lingan architecture. From the fact that the Xiguan
Mansion, an "object", has reasonable relationship thread, the reason for the formation of its artistic style can be explored.

Xigau, Guangzhou was a commercial and trade center formed in the Ming and Qing Dynasties. The Xiguan Mansion was a residence built by merchants and millionaires in the downtown area. In its heyday, the Xiguan Mansion had up to 800 rooms. To protect family privacy and guard against theft in the downtown area, the Xiguan Mansion was built with a "triad" entrance, usually having three gates. Facing the street is the patterned gate, four hinged screen doors inlaid with pattern glass or lined with crocheted curtains in the upper, and decorated with symmetrical wood carvings at the two top corners to obstruct the view of passers-by, without prejudice to lighting and ventilation. The sliding bar doors behind the patterned gate have distinctive Lingnan features. Sliding is to open, and bars are to close, so that the sliding bar doors are a kind of sliding wood door. Behind the bars are the heavy doors to guard against theft.

As the climate in Lingnan is hot, wet, and rainy, the Xiguan Mansion generally adopts open and transparent planes and spatial layout, with open porches, windows, and doors as the transition and link of indoor and outdoor space; dwellers are fond of social interaction or family reunion activities and prefer an easy and vivacious life style, so that the color focuses on solid color such as light cyan, light blue, light green to weaken the sense of weight. In this way, the building feels ethereal, lucid, and elegant; under the influence of the excellent style of traditional architecture, the hall of the Xiguan Mansion is built along the central axis to be two and three rows. Between the rows is a small courtyard, employing a skylight for lighting and ventilation; influenced by overseas cultures, the decoration or furnishing of the architecture has a tone of Western styles to an extent.

In terms the target system from the natural condition of geology, climate, etc. to the humanistic deposits of historical tradition, social life, etc., the Xiguan Mansion in Guangzhou evolves to be an "object" of artistic style, a typical examplefrom the designed "object" to the created "affairs". From finding and observing problems in life, a probe is made to the nature of objects to propose concepts and schemes of systematically solving the problems, so as to realize the leap from the designed "object" to the created "affairs". Beyond the imagination and getting hold of the element, design not only depends on better "objects" to serve people, but also rests on "objects" to create a new life style, that is, to create "affairs". 


\section{INHERITANCE OF THE ARTISTIC STYLE OF LINGNANARCHITECTURE}

The development of the artistic style of Lingnan architecture goes a step further in terms of the science of human affairs. With respect topragmatism, it focuses on reality and practicality; with respect to compatibility, it draws on successful experience from others, both ancient and modern, Chinese and foreign; with respect to people orientation, it is directed to people; with respect to innovation, it keeps peace with the times by originality.

\section{A. Architectural Art Style Blending with the Nature}

In terms of design, Lingnan architecture stresses obedience to the objective factors of "affairs", for example, the processing of natural environment, the fulfilment of modern functions, and the use of new materials and technology, and emphasizes the sufficient and organic bond with nature and environment, so as to exhibit the advantages of the natural state and realize unification between objective factors and artistic style of architecture in appearance, space, and structure, and thus to grasp the reversion and the affinity of buildings to nature.

\section{B. Architectural Art Style Blending with the Surrounding Buildings}

The design of Lingnan architecture underlines the relationship context of "affairs", requiring the artistic style of the architecture to combine the surrounding environment and buildings into a whole. Relying on environmental condition, the artistic style of Lingnan architecture appropriately solves the problem that buildings are in harmony to the environment and in unity with surrounding complexes.

Taking the design of the surrounding buildings of the Sun Yat-sen Memorial Hall as an example, in designing Guangzhou Official Bureau, now Guangzhou Municipal Government, in 1934, to match the surrounding environment and style of the Sun Yat-sen Memorial Hall, the Bureau's office buildings adopted a similar palatial style, roofed with yellow glazed tiles and placed with a ceiling decorated with traditional Chinese patterns. When the Guangdong Science Museum was built in 1956, it was integrated with the Sun Yatsen Memorial Halland the Official Bureau into a complete and harmonious complex.

\section{Inclusive and Open Architectural Art Style}

The artistic style of Lingnan architecture integrates Chinese and the Western based on self-consciousness, and create "objects" in heritance, innovation, abandoning, and development. The accommodation and openness of the Lingnan culture make the artistic style of Lingnan Architecture have both Chinese and Western characteristics, and exhibit the inclusive and open features of thisarchitectural culture as an external representation of the artistic style of Lingnan architecture. This artistic style of architecture is vividly presented in much architecture like gardens, houses in Lingnan in recent years.

\section{Pioneering Architectural Art Style}

Innovation is the soul, the common pursuit and goal of architects, and an important link in the science of human affairs. With the progress of the times and the development of social productivity, following predecessors like sheep and failing to unfold the two dimensions of the "time stream" and "space field" of "affairs" are not helpful for the innovation of "affairs". The artistic style of Lingnan architecture has strong innovation consciousness and is quick in action.

Memorial Hall of Lingnan School of Painting is a representativeof the artistic style of Lingnan architecture in innovation. The innovatively abstract elements of Lingnan architecture allow its artistic style to be in good agreement with the artistic conception of the painting school, showing poetic illusions of abstract Lingnan architecture and realizing the innovation of creating "objects".

\section{INNOVATION IN THE ARTISTIC STYLE OF LINGNAN ARCHITECTURE}

\section{A. Harmonious Unification with Regional Environment in Innovation}

The "affairs" in the design of Lingnan architecture concern more about the correlation between the elements. This rational design thought stresses the interaction and inter-collision of these individual elements, which will have an impact on every corner of architecture; it also emphasizes regional natural condition, climatic elements, latent culture, and technical elements, turns "the implicit" into "the explicit", and make it more regional, cultural, and epochal, bringing about a creative architectural art style that is pragmatic, open, transparent, and graceful.

Guangzhou Opera House completed in 2009 is a representative. Standing adjacent to the Pear River on the center of Guangzhou New City, Guangzhou Opera House, based on the concept of "double pebbles" and the element of the explicit regional feature-the Pearl River, is an irregular "Pearl River Rock" in shape, which, powerful and vigorous, is strongly iconic and futuristic.

With the strong geometric order and the artificially shaped skyscrapers along both sides of the longitudinal axis, Guangzhou Opera House shows a salient feeling of depth. At the intersection of the vertical direction and the horizontal direction, the Opera House, like a Lingnan garden, dramatically flexes freely on the metropolitaninterface by its horizontally stretched body. Guangzhou Opera House and its square, the continuous change in the declination from the edge to the center, and the subtle ground relief successfully soften the metropolitan interface at the intersection of the longitudinal and horizontal axes. Through the overlapping of the natural appearance and the artificial geometric shapes, the penetration of natural environment and architectural environment, and the complete and continuous body and its façade texture processing, the context of "affairs" can be clearly seen, which explicitly conveys the internal logic between individual buildings and the city, stresses the dialog between the spectacular naturaldimension represented by the Pearl River and the humanistic dimension represented by the Opera House. 
In this way, the whole space of the city is completed, and architectural design and its artistic style blend with urban design, and finally the innovation in "objects" is attained.

\section{B. Inheritance and Innovation of Cultural Environment}

The innovation of the artistic style of Lingnan architecture finds expression in the inheritance and creation of the historical and cultural environment of Lingnan. Starting from designing "affairs", it seeks its roots from Lingnan culture and tradition, explores beneficialcultural genes, combines with modern science, technology, and culture, and realizes the shaping of the originality of "objects", to make modern architecture regionalized, regional architecture modernized and to attain conveyance, inheritance, and development of national and traditional culture.

The artistic style of Lingnan architecture is engraved with the imprint of Lingnan natural environment. The subtropical ecological environment has created the remarkably different cultural characteristics from the Central Plains. Backing on the continent and facing the seas, Lingnan culture has experienced the impact of the intersection and integration of maritime civilization and inland civilization to blend the cultural ethos, ancient and modern, Chinese and overseas. Based on Baiyue culture, Lingnan culture has integrated central plain culture, Chu culture, Wuyue culture, Bashu culture, etc., to further form a regional culture in the long exchange with various cultures. Meanwhile, the world's advanced cultures and concepts are absorbed and digested along with the development of Lingnan maritime culture. Therefore, Mercantilism, openness, compatibility, diversification, enjoyment, visibility, and Confucianism exclusion are basically characteristic of Lingnan culture. Thus, the soul of the artistic culture of Lingnan architecture lies in its openness, compatibility, and innovation.

The Museum of the Western Han Dynasty Mausoleum of the Nanyue King is the representative of Lingna architecture art style's inheriting and innovating cultural environment. The experience of the reversion of architecture to nature and the affinity of architecture to the environment is the museum's pursuit of the intimacy between architecture and the environment, nature, and gardens in a complete and integrated open space.

The cultural connotation of the artistic style of the museum stands rooted in natural environment and climate. Meanwhile, it protects and continues the original culture, maintaining the consistency of the environment of Nanyue culture as well.

The Museum of the Western Han Dynasty Mausoleum of the Nanyue King has a high content of regional history and cultural information in the Western Han Dynasty and lots of scientific, humanistic, and cultural materials such as topography and landforms, plants and animals, construction technology, and ecological environment. The combination of the characteristics of Han Dynasty culture of nearly two thousand years with Lingnan distinctive regional environment, and of the red sandstone, a local material in Lingnan with the modern architectural techniques of expression of forms and space, as well as the ancient Nanyue's architectural culture and thought, forges high-grade spatial and cultural forms with strong environmental awareness and shapes the Lingnan architectural culture and artistic style both inheriting the history and pursuing development and innovation.

\section{REFERENCES}

[1] Liu Guanzhong. Beyond Imagination Works-Quotation, Interviews, Essays, Opinions [M]. Beijing: China Architecture \& Building Press, 2012.

[2] Tang Xiaoxiang. The Culture and Aesthetics of Contemporary Lingnan Architecture [M]. Beijing: China Architecture \& Building Press, 2010.

[3] Mao Yalong, He Jingtang, GuoWeihong. LingnanArchitectural School and Its Design within the Concept of Fractal Theory $[\mathrm{J}]$. South Architecture, 2014(1):88-93.

[4] He Jingtang. He Jingtang Architectural Design [M]. Guangzhou: South China University of Technolgy Press, 2010.

[5] Li Wei. Cultural Study Turns of Lingnan Architectural SchoolCommentary on 2012 Symposium of "Lingnan Architectural School and Lingnan Architectural Innovation" [J]. academic research, 2013(1). 